\title{
Study of the Impact of Rainfall Trends on Landslide Frequencies; Sri Lanka Overview
}

\section{T. D. Rathnaweera and U. P. Nawagamuwa}

\begin{abstract}
Landslides related to heavy rainfall cause widespread property damage and occasional loss of lives. During the last ten years it has become evident that the most devastating landslide events tend to occur as a result of comparatively short duration, high intense rainfall compared to the previously had lower intense prolonged rainfalls. At a time when climate change and global warming issues are considered as hot topics, it is required to evaluate the changes and their impacts on landslides frequencies in Sri Lanka. This study looks at extreme rain conditions in the context of climate change in landslide prone districts in Sri Lanka. Mainly two trend patterns, seasonal distribution of landslides and Annual total time series distribution of landslides were developed to get the effect of climate changes in selected landslide prone districts in Sri Lanka. Identification of extreme rainfall conditions were done based on data collected from the Department of Meteorology, Sri Lanka. The possible trends are discussed using above rainfall variations and the collected landslide frequency data.
\end{abstract}

Keywords: Climate change, Landslides, Rainfalls

\section{Introduction}

Today, the problem of landslides has aggravated in South Asia as well as in the other part of the world. The mitigation of, and adaptation to the effects of the global climate changes are now the greatest challenges for humanity. Global climate change is possibly impacting the frequency of landslide in the world and will continue to do so in the future [3]. An independent review of more than one and a half billion temperature records from fifteen sources over more than a century clearly shows that the planet is warming [10]. Researchers at the University of California, Berkeley have confirmed previous reports that global temperatures have risen by 1 degree Celsius or nearly two degrees Fahrenheit overall (See Figure 1).

Buma and Dehn, (1998) have demonstrated the linkages between climate change and landslide activity in Europe. Most of the investigations of the effect of climate change on landslide frequencies suggest an increase in both rainfall and temperature over the next century around the world. Climate change scenarios for SE England concluded this change is likely to have a number of potentially contradictory impacts on different types of mass movement process in the SE England [2].Research findings indicate that the average temperature of the earth has risen by $0.7^{\circ} \mathrm{C}$ over the past 100 years due to the emission of greenhouse gasses. The last few decades have been identified as the warmest period in the last thousand years [9].

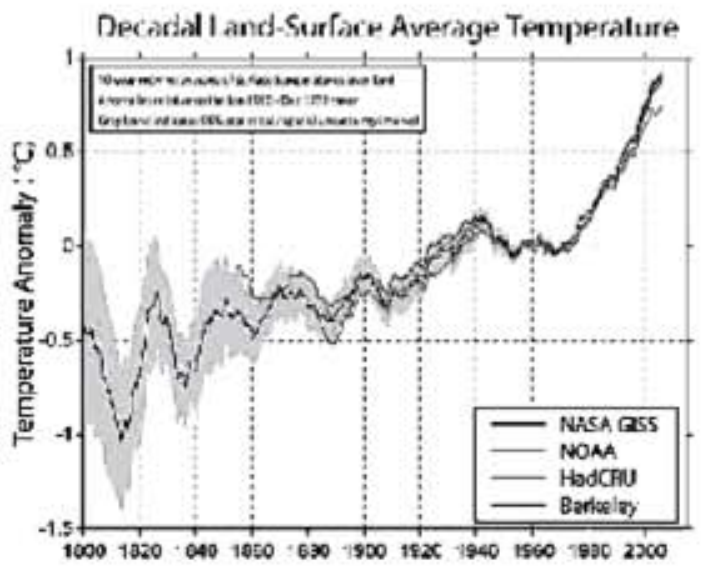

Figure 1 - Decadal land- surface average temperature variation (University of California, 2001)

Undisputed evidence has now confirmed that the global temperature has been increasing during the last few decades due to global warming as a result of increasing greenhouse gases [1].

T. D. Rathnaweera,B.Sc.Eng.(Moratuwa).

Eng. (Dr.) U. P. Nawagamuwa, B. Sc. Eng.(Moratuwa), M.Eng. (AIT), Dr. Eng. (YNU), CEng, MIE(Sri Lanka),Senior lecturer of Civil Engineering, Department of Civil Engineering, University of Moratuwa,Sri Lanka. 
Climatic conditions predicted from worldwide global warming involve new precipitation and wind conditions. These will significantly affect the amount and type of vegetation, groundwater levels and surface water levels. All these factors will affect the stability of certain natural slopes due to losses of soil suction, higher groundwater tables, increase in seepage velocities, frequent occurrences of rapid drawdown conditions, losses of soil reinforcement contributed by roots and losses of stabilizing materials through erosion from flooding [3].

Considering the above facts, possible correlations between extreme rainfall conditions and landslide frequencies were studied in selected landslide prone districts of Sri Lanka. The information gathered from local administrators and engineering geology consultants, as well as from interviews with inhabitants, could suggest that starting from the second half of 2001, there has been an increase in landslide activity in many urban and periurban areas in Sri Lanka [1].

This research paper explores the variation of extreme rainfall conditions with respect to spatial distribution of landslides in Sri Lanka over the span of last ten years. The research also compares the obtained trend patterns with different countries such as Italy, England and Brazil.

\section{Methodology}

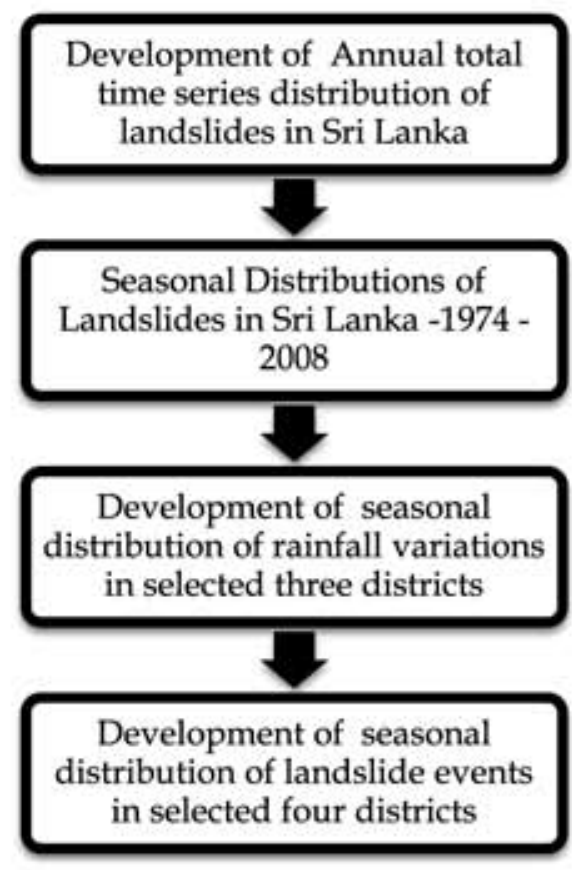

The interrelationships between the rainfall variations and the landslide events were done using the data collected from Meteorological department and Disaster Management Centre of Sri Lanka. Four landslide prone districts were selected to develop the possible trend. Figure 2 illustrates the methodology of identification of possible rainfall trends in landslide frequencies in Sri Lanka.

\section{Results and Discussion}

Figure 3 shows the time series distribution of landslides in Sri Lanka during last 34 year period. Overall, the amount of landslide events per year has been increased over the period of 34 years. Moreover, it is clear that there was a sudden increase in the occurrence of landslides during the period from 2002 to 2008. Landslides were previously considered as a minor type of disaster and not a common occurrence in Sri Lanka. Until the year 2002, the annual average number of landslide records did not exceed 50 [6].

In the complete dataset for the period 19742008, it has recorded a total of 732 fatal landslides in Sri Lanka. Analysis of these annual data shows that the number of fatalities varies greatly from year to year. A smaller number of landslides occurred between 1974 and 1985, whereas the largest number was 362 in 2007. There appears to be some interesting underlying trends in the data, with distinct periods when the number of fatal landslides increase (1985-1997 and 2002- 2007) and periods when the numbers are substantially lower (1974-1985 and 1997-2002). It is also notable that there appears to be a general increasing trend, with the five most deadly years all occurring in the period 2003-2007. However it should be noted that this is not a simple upward trend, as a peak in fatalities and numbers of landslides occurred in the period 2003-2007, and a decline is noted thereafter.

Figure 3 clearly concluded that the trend pattern has a 3.651 annual average increment in the landslide frequency in Sri Lanka during the period from 1974 to 2008. Considering the above fact separate attention was given to study the possible trends in each landslide prone districts during the last decade in Sri Lanka.

Figure 2- Methodology Flow Chart 


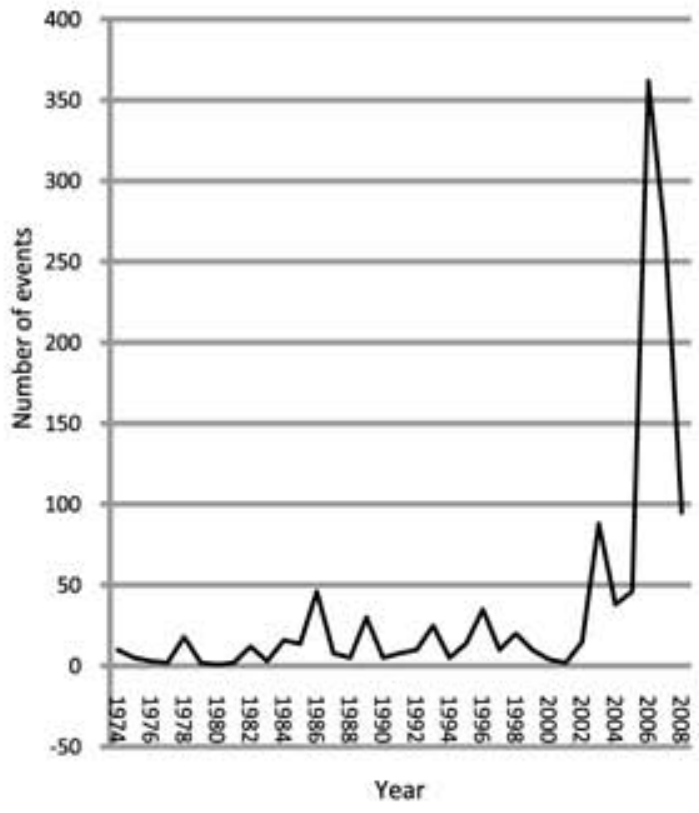

Figure 3- Annual total time series distribution of landslides in Sri Lanka during last decade [6]

Table 1- Observed trend patterns on landslide frequencies in Sri Lanka

\begin{tabular}{|l|c|}
\hline \multicolumn{1}{|c|}{ District } & $\begin{array}{c}\text { Observed trend pattern(Events per } \\
\text { year) }\end{array}$ \\
\hline Ratnapura & 1.0 \\
\hline Badulla & 13.0 \\
\hline NuwaraEliya & 25.0 \\
\hline Kandy & 1.0 \\
\hline
\end{tabular}

Considering the above facts development of seasonal distribution of landslides in Sri Lanka was done.

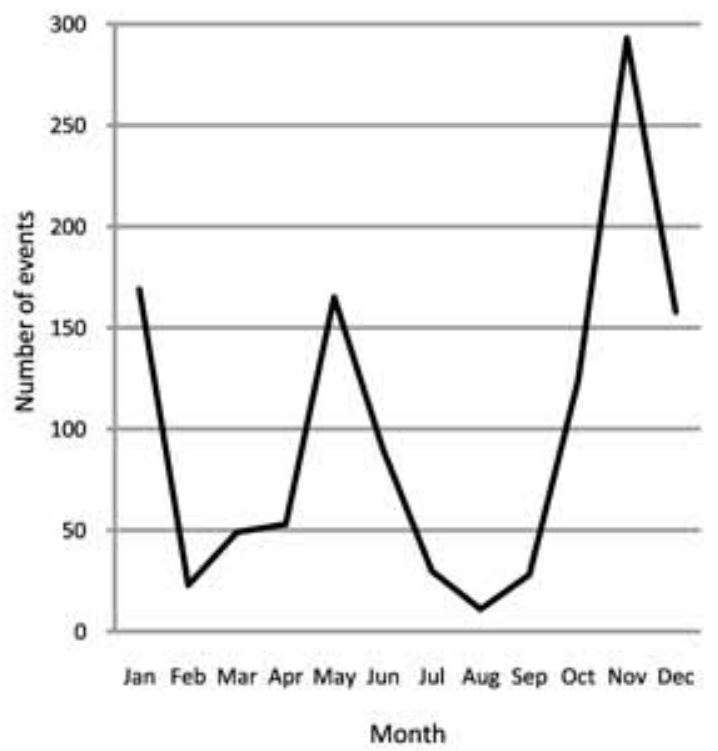

Figure 4- Seasonal Distributions of Landslides in Sri Lanka from 1974 to 2008[6]
According to the figure 4, the second peak is higher than the first and November has the highest recorded landslides, exceeding more than 275 incidents. It is well known that Sri Lanka has two monsoon seasons. The records of landslides are high in the months of May and June and from November to January, showing a clear relationship with two monsoon seasons in Sri Lanka. This conforms that the landslides in Sri Lanka are rainfall induced. There are no significant recorded landslide fatalities in the period from February to April and from July to September, reflecting the relative dry conditions in Sri Lanka.

Figures 5, 6 and 7 show the seasonal distribution of landslides in South Asia, East Asia and South- East Asia.

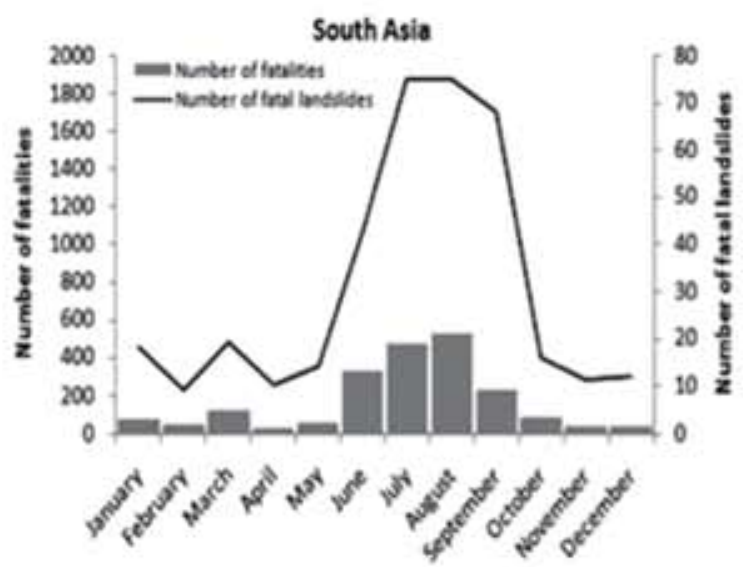

Figure 5- Monthly recorded fatal landslide occurrence (line graph) and loss of life (bar graph) for South Asia [8]

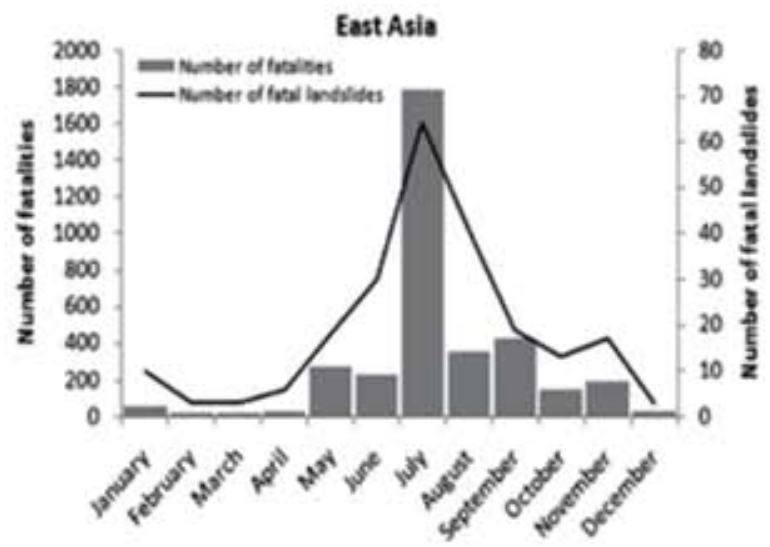

Figure 6- Monthly recorded fatal landslide occurrence (line graph) and loss of life (bar graph) for East Asia [8] 


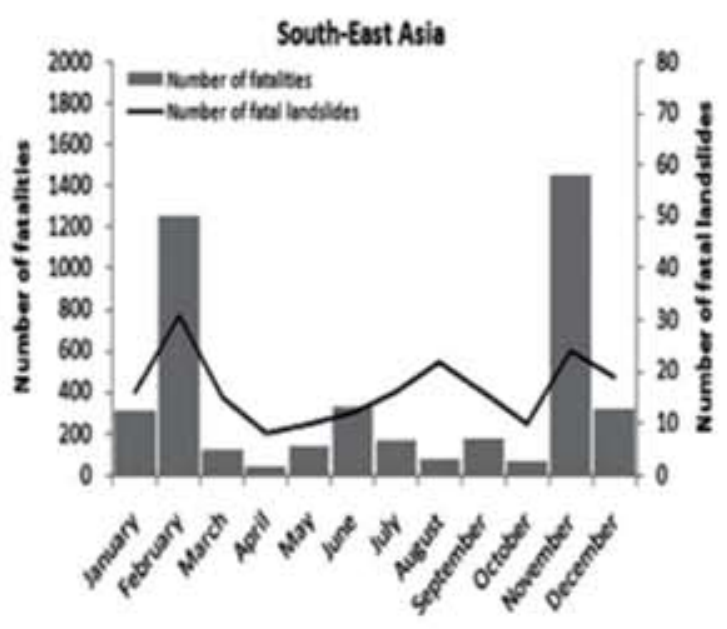

Figure 7 - Monthly recorded fatal landslide occurrence (line graph) and loss of life (bar graph) for South-East Asia[8]

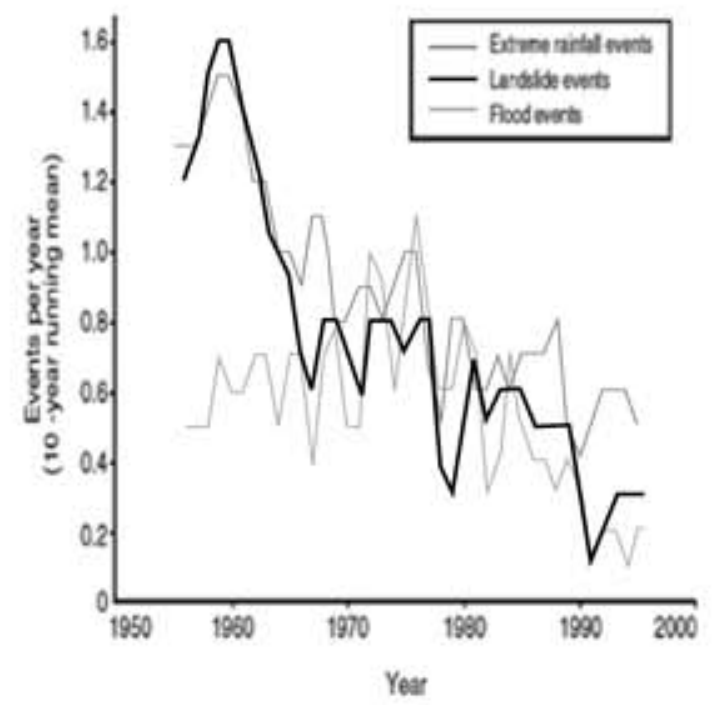

Figure 8 - The variation of extreme rainfall events and the landslide frequencies in Italy[7]

Figure 8 illustrates the interrelationship between extreme rainfall events and the landslide events in Italy over the span of fifty years. The authors analysed 50 years of rainfall records (1951-2000) from the eastern Basilicata region of southern Italy, concentrating on characterizing trends in extreme rainfall events, as well as resultant flood events and landslide events. Working with the data plotted in the Figure 8, Clarke and Rendell (2006) determined that "the frequency of extreme rainfall events in this area declined by more than $50 \%$ in the 1990 s compared to the 1950s." In addition, the research reported that "impact frequency also decreased, with landslide-event frequency changing from 1.6/year in the period 1955-1962 to 0.3 /year from 1985 to 2005 , while flood frequency peaked at 1.0 /year in the late $1970 \mathrm{~s}$ before declining to less than 0.2 /year from 1990."The world's climate alarmists continue to claim that global warming will lead to large increases in various types of extreme weather events, based on model-derived IPCC storylines(The Intergovernmental Panel on Climate Change). Some of them additionally claim that the planet's near-surface air temperature is now at a level that is less than $1^{\circ} \mathrm{C}$ below the maximum temperature of the past million years [7], which would suggest that extreme weather events must have risen dramatically almost everywhere over the last quarter-century. However, Clarke and Rendell's (2006) results differ radically from this scenario; and they have concluded from their analyses of real-world data that if the climatedriven changes they observed over the latter part of the 20th century would continue, "the landscape of southern Italy and the west-central Mediterranean will become increasingly stable," or as the authors say in their concluding paragraph, "increased land-surface stability will be the result." The research has shown that there was no relationship between landslide events and global climate change in Italy. In Sri Lanka, the variation was very different to the above discussed Italica study. It has shown that the both rainfall variations and the landslide events have positive increments during the last 10 year period. Considering the local trends, developments of seasonal variations of the rainfall was done to study the correlation between climate change and landslide frequencies. Figures 9, 10 and 11 illustrate the rainfall movements of selected three landslide prone districts in Sri Lanka during the last decade. 


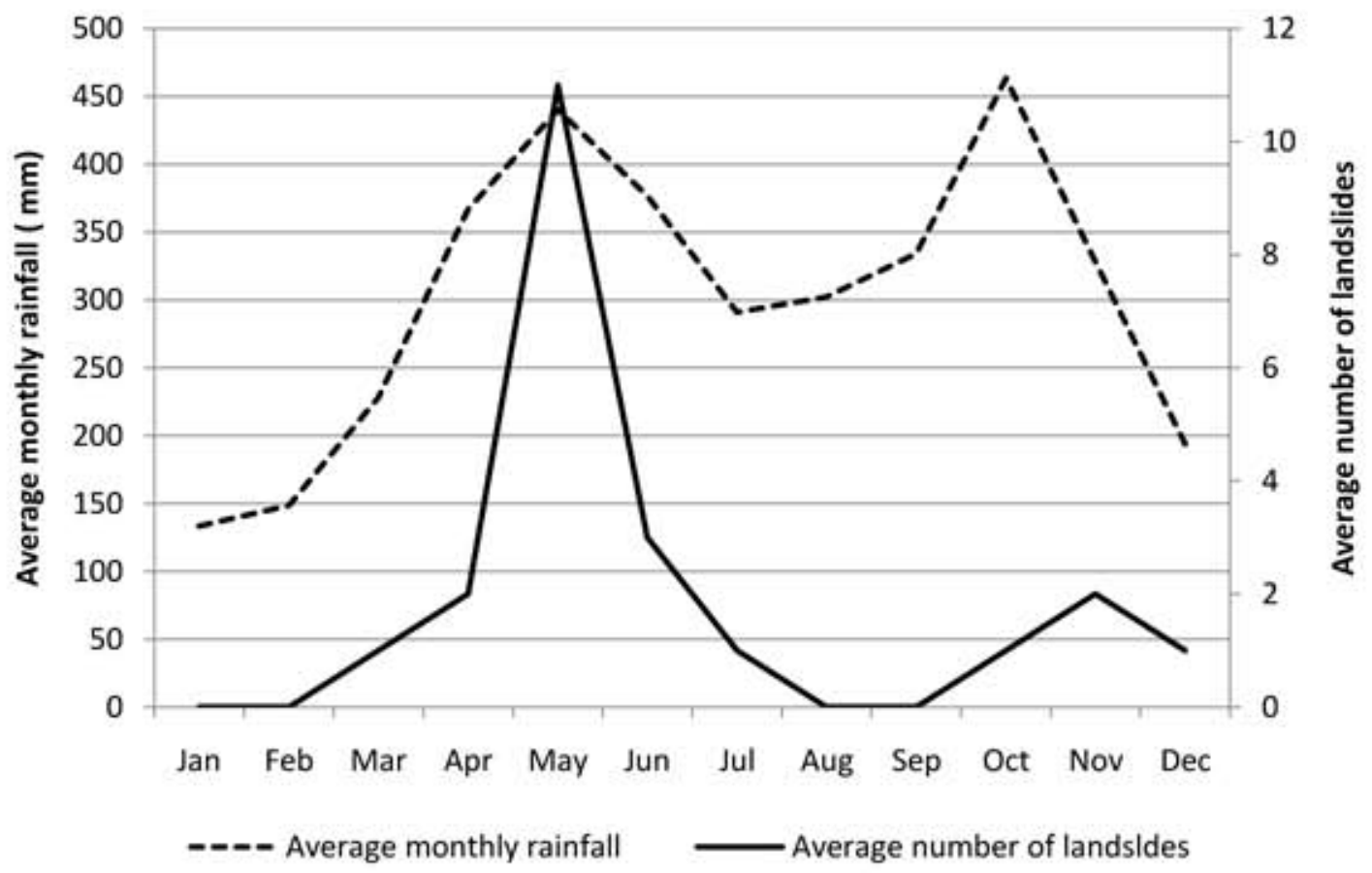

Figure 9 - Relationship between average monthly rainfall variation and average number of landslide occurrences in Ratnapura district during the last decade

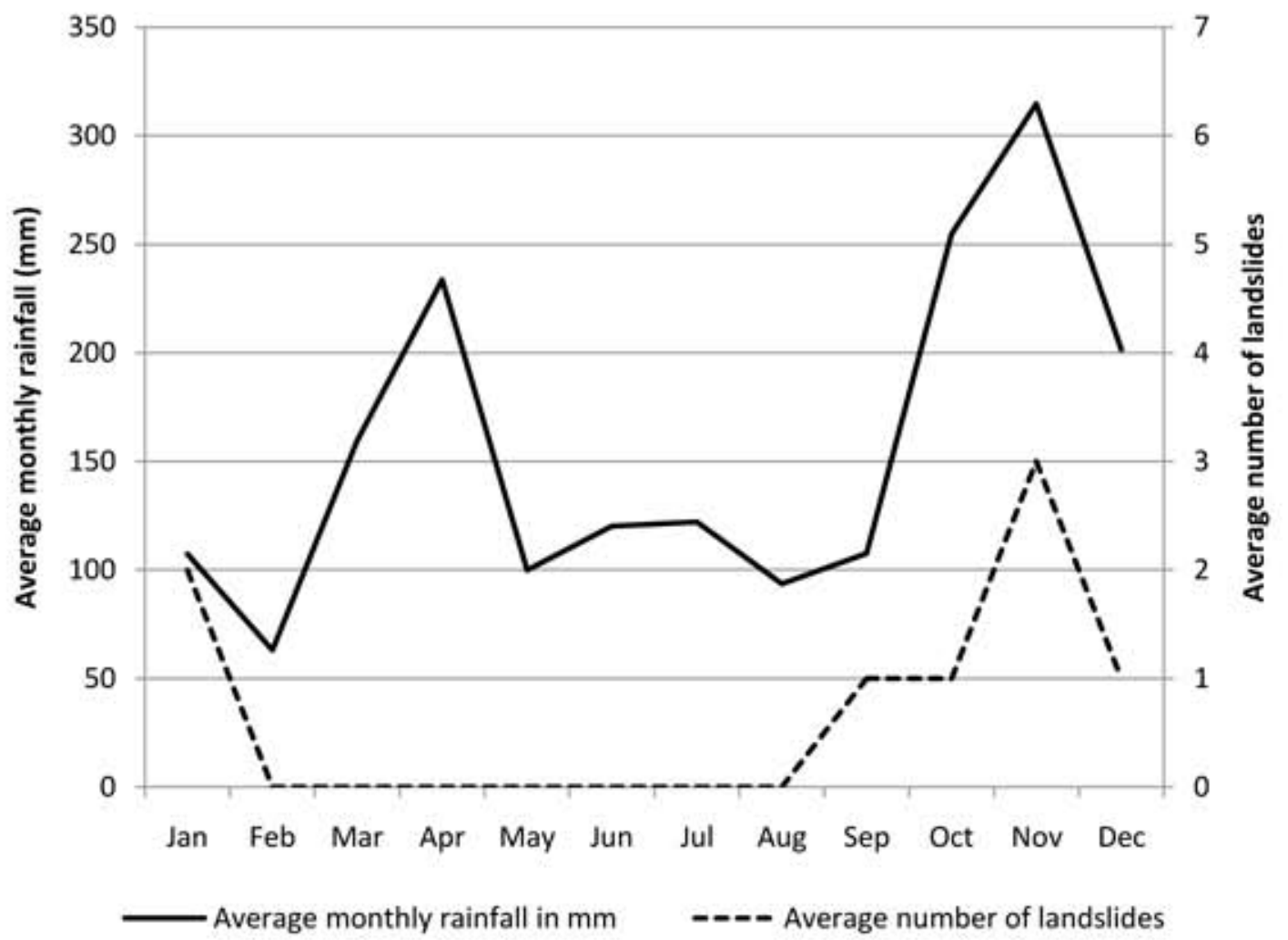

Figure 10- Relationship between average monthly rainfall variation and average number of landslide occurrences in Kandy district during the last decade 


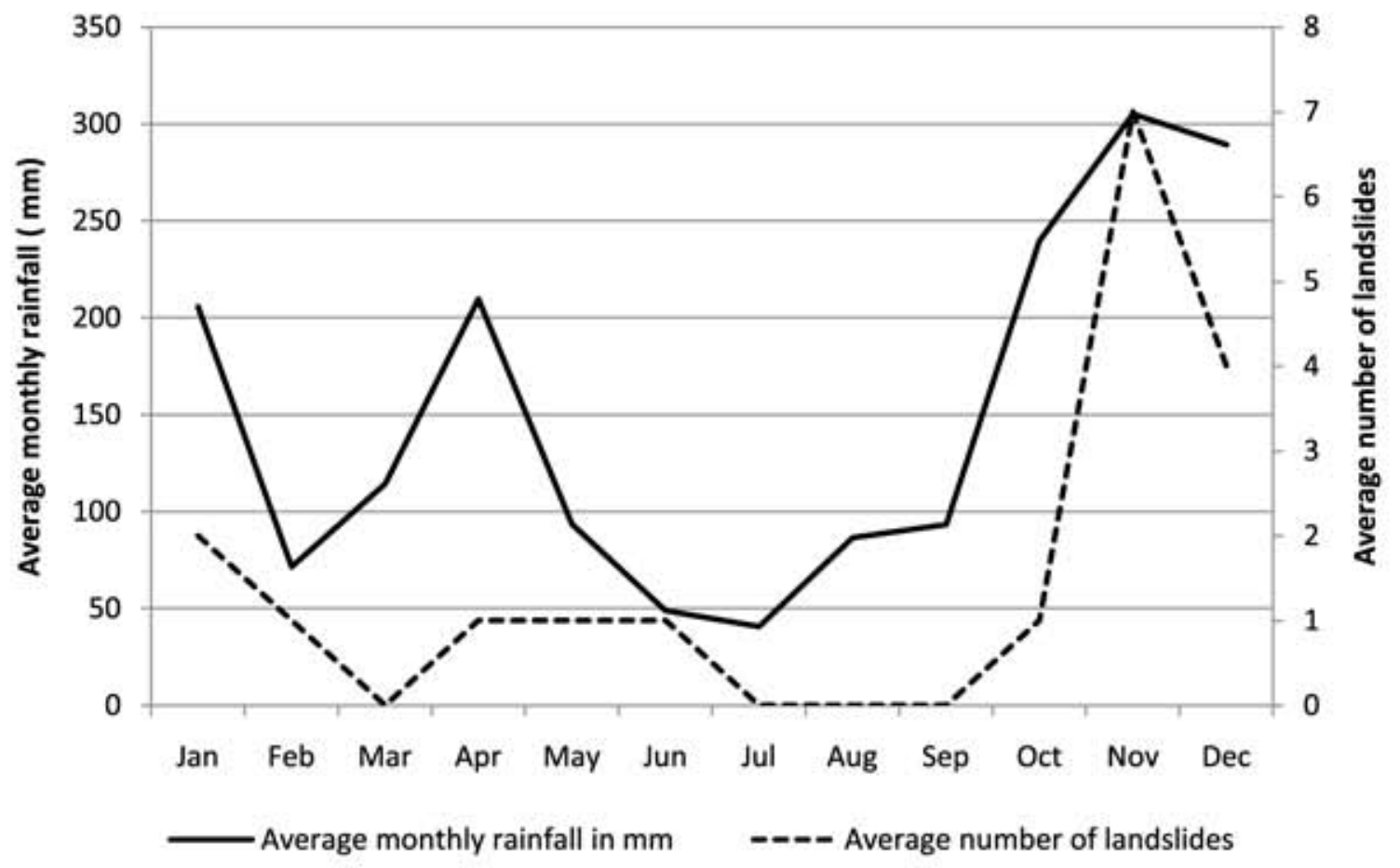

Figure 11- Relationship between average monthly rainfall variation and average number of landslide occurrences in Badulla district during the last decade

Based on the climate change scenario in Sri Lanka, evaluation was done to identify the effect of climate change in landslide frequencies. Considering the selected five landslide prone districts, development of annual rainfall variations was done. Annual cumulative rainfall data was calculated by using cumulative monthly rainfall data which was collected from the department of Meteorology of Sri Lanka. Identification of the trend patterns of the annual rainfall was done for the last 10 year period. The trend patterns in Figure 12 show the significant increments of the annual rainfall in selected landslide prone districts in Sri Lanka.

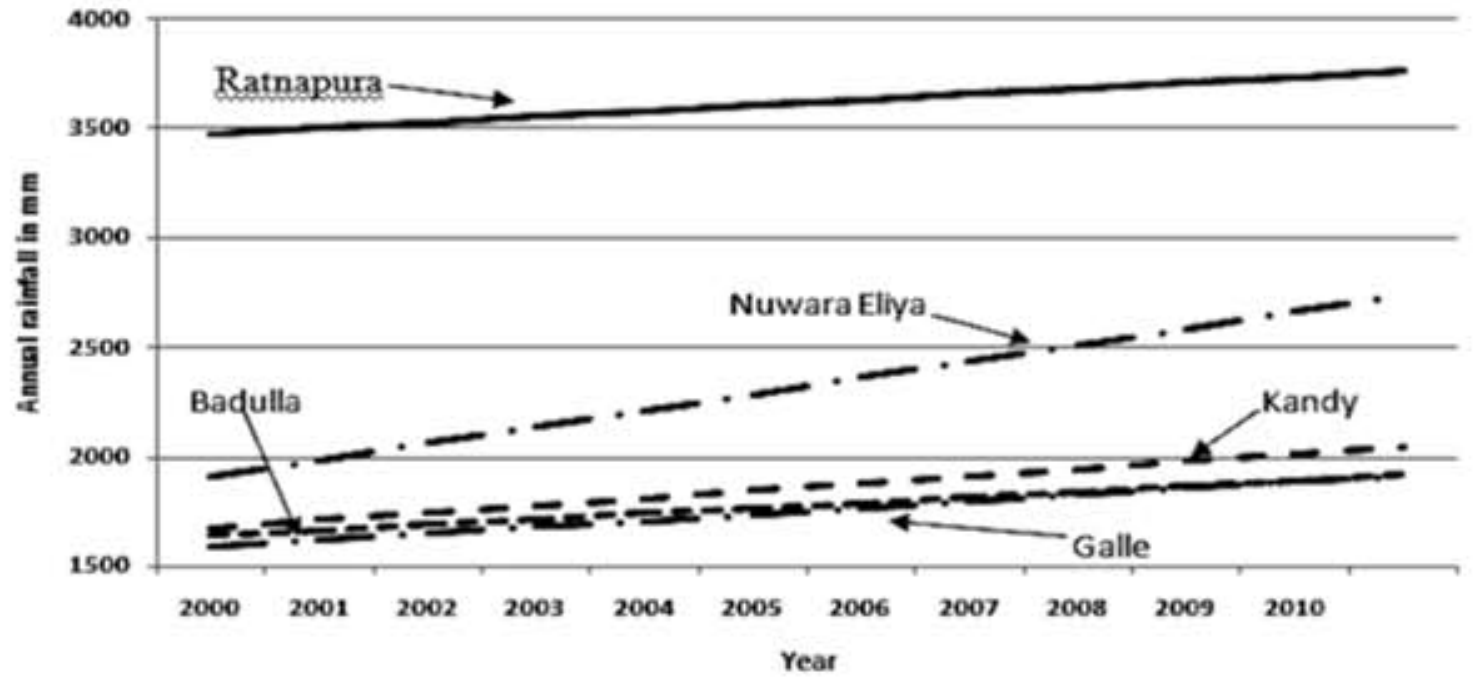

Figure 12- Annual rainfall trend patterns in selected landslide prone districts of Sri Lanka during the last decade 
Since the annual average rainfall trend patterns clearly shows an increment, the effect of the wettest month rainfall patterns and the driest month rainfall patterns were also studied to find further relations. The trend patterns of the wettest month rainfall in selected landslide prone districts show increments in the monthly rainfall in Ratnapura, ì̀ waraEliya, Kandy and Galle whereas Badulla district shows some deviation from the other selected districts (See Table 2). The trend patterns also clarified that the wettest month in each district has experienced more rain during the past 10 years.

Table 2- Observed changes in wettest month monthly rainfall in selected landslide prone districts in Sri Lanka

\begin{tabular}{|l|c|}
\hline \multicolumn{1}{|c|}{ District } & $\begin{array}{c}\text { Observed trend } \\
\text { pattern(mm per month) }\end{array}$ \\
\hline Ratnapura & +2.13 \\
\hline Kandy & +22.17 \\
\hline Nuwara Eliya & +4.95 \\
\hline Galle & +2.23 \\
\hline Badulla & -10.32 \\
\hline
\end{tabular}

Table 3 summarises the observed changes of monthly rainfall variations in the driest months where the trend patterns of monthly rainfall have decreased during last decade except in Badulla district.

Table 3- Observed changes in monthly rainfall in the driest months in landslide prone districts in Sri Lanka during the last decade.

\begin{tabular}{|l|c|}
\hline \multicolumn{1}{|c|}{ District } & $\begin{array}{c}\text { Observed trend pattern(mm } \\
\text { per month) }\end{array}$ \\
\hline Ratnapura & -9.32 \\
\hline Kandy & -7.43 \\
\hline NuwaraEliya & -7.90 \\
\hline Galle & -2.24 \\
\hline Badulla & +0.85 \\
\hline
\end{tabular}

Considering the landslide events of the Table 4 , it is clear that most of the landslides occurred due to the short duration high intense rainfall. It is also clear that the extreme weather conditions like short duration high intense rainfall patterns have also increased during the last decade. This could be possibly due to climate change. If the increments of the extreme weather conditions happen due to the climate change, then it will prove that the effect of climate change is directly affecting the landslide frequencies in Sri Lanka.

Table 4- Observed information of landslide events in Sri Lanka during last decade

\begin{tabular}{|c|c|c|c|}
\hline District & $\begin{array}{c}\text { Date of } \\
\text { occurrence }\end{array}$ & $\begin{array}{l}\text { Maximum } \\
\text { daily } \\
\text { rainfall } \\
(\mathrm{mm})\end{array}$ & $\begin{array}{l}\text { Duration } \\
\text { of the } \\
\text { rainfall } \\
\text { (hrs) }\end{array}$ \\
\hline Ratnapura & $17-05-2003$ & 345.2 & 2 \\
\hline Ratnapura & $21-07-2008$ & $\begin{array}{l}\text { 186.1- } \\
\text { Three } \\
\text { days } \\
\text { before the } \\
\text { landslide }\end{array}$ & 3 \\
\hline Badulla & $20-12-2006$ & 108.4 & 1 \\
\hline NuwaraEliya & $12-01-2007$ & $\begin{array}{l}\text { 77.6- Two } \\
\text { days } \\
\text { before the } \\
\text { landslide }\end{array}$ & 1 \\
\hline
\end{tabular}

\section{Conclusions}

In the present study an attempt was made to analyse possible relationships between the patterns of rainfall and the landslide frequencies.

The study has been focused on one climatic factor. However, this study does throw some light on the relation between climatic parameters and the frequencies of landslide. The analyses have shown that the possible trends of landslide events have always followed the path of two monsoons.

Overall, it is clear that the variations of the landslide frequencies and rainfall events in Sri Lanka have shown some deviations from the trends of South Asia, East Asia, South East Asia and Italy. 


\section{Acknowledgements}

Climate Studies Division of Meteorology Department of Sri Lanka is kindly acknowledged for providing necessary data for the analysis. Authors also wish to thank National Building Research Organization (NBRO) and Disaster Management Center of Sri Lanka (DMC).

\section{References}

1. ADPC and AUDMP safe cities 12, 2005. "Case Studies on Mitigating Disasters in Asia and the Pacific, Demonstration Housing Construction for Landslide and Flood Prone Areas, A Case Study from Ratnapura, Sri Lanka".

2. Andrew, C., Steven, W., Jim, G., and Martin, D., 2000. "Modelling the Impact of Predicted Climate Change on Landslide Frequency and Magnitude in SE England, Eng, Geology 55, 205- 218.

3. Bo, M. W., Fabius, M and Fabius, K., 2008. "Impact of Global Warming on Stability of Natural Slopes, Geohazards 4.

4. Buma, J., Dehn, M., 1998. "A Method for Predicting the Impact of Climate Change on Slope Stability". Environ, Geol. 35, 190- 196.

5. Clarke, M.L. and Rendell, H.M. 2006. Hindcasting Extreme Events: The Occurrence and Expression of Damaging Floods and Landslides in Southern Italy. Land Degradation \& Development 17: 365-380.

6. DMC Report, 2009 "Sri Lanka National Report on Disaster Risk, Poverty and Human Development Relationship".

7. Hansen, J., Sato, M., Ruedy, R., Lo, K, Lea, D.W. and Medina-Elizade, M. 2006. Global Temperature Change. Proceedings of the National Academy of Sciences USA 103: $14,288-14,293,2006$.

8. Petley, D.N. 2010. "An Analysis of Fatal Landslides in the Asia-Pacific Region for 2006 to $2008^{\prime \prime}$.

9. Virginia, H. Dale., Linda, A. Joyce., Steve, Mcnulty., Ronald, P. Neilson., Matthew, P. Ayres., Michael, D. Flannigan., Paul, J. Hanson, Lloyd, C., 2001. "Climate Change and Forest Disturbances", Vol. 51 No. 9 Bioscience 723.
10. Zarrien, A., 2010. "Effect of Temperature and Rainfall as a Component of Climate Change on Fish and Shrimp Catch in Pakistan", The Journal of Transdisciplinary Environmental Studies, vol. 9, no. 1. 